\title{
Piperine metabolically regulates peritoneal resident macrophages to potentiate their functions against bacterial infection
}

\author{
Hao Pan ${ }^{1, *}$, Li-Hui Xu' ${ }^{2, *}$, Mei-Yun Huang ${ }^{1}$, Qing-Bing Zha ${ }^{3}$, Gao-Xiang Zhao ${ }^{1}$, Xiao- \\ Feng Hou ${ }^{1}$, Zi-Jian Shi ${ }^{3}$, Qiu-Ru Lin ${ }^{1}$, Dong-Yun Ouyang ${ }^{1}$ and Xian-Hui He ${ }^{1}$ \\ ${ }^{1}$ Department of Immunobiology, College of Life Science and Technology, Jinan University, Guangzhou, China \\ 2 Department of Cell Biology, College of Life Science and Technology, Jinan University, Guangzhou, China \\ ${ }^{3}$ Department of Fetal Medicine, the First Affiliated Hospital of Jinan University, Guangzhou, China \\ * These authors have contributed equally to this work \\ Correspondence to: Dong-Yun Ouyang, email: dongyun1967@aliyun.com
}

Xian-Hui He, email: thexh@jnu.edu.cn

Keywords: bacterial infection, mTORC1, peritoneal macrophages, piperine, SLC7A5/SLC3A2, Immunology and Microbiology Section, Immune response and Immunity

Received: July 07, $2015 \quad$ Accepted: September 12, $2015 \quad$ Published: October 02, 2015

This is an open-access article distributed under the terms of the Creative Commons Attribution License, which permits unrestricted use, distribution, and reproduction in any medium, provided the original author and source are credited.

\section{ABSTRACT}

Pepper, a daily-used seasoning for promoting appetite, is widely used in folk medicine for treating gastrointestinal diseases. Piperine is the major alkaloid in pepper and possesses a wide range of pharmacological activities. However, the mechanism for linking metabolic and medicinal activities of piperine remains unknown. Here we report that piperine robustly boosts mTORC1 activity by recruiting more system L1 amino acid transporter (SLC7A5/SLC3A2) to the cell membrane, thus promoting amino acid metabolism. Piperine-induced increase of mTORC1 activity in resident peritoneal macrophages (PMФs) is correlated with enhanced production of IL-6 and TNF-a upon LPS stimulation. Such an enhancement of cytokine production could be abrogated by inhibitors of the mTOR signaling pathway, indicating mTOR's action in this process. Moreover, piperine treatment protected resident pMФs from bacteriuminduced apoptosis and disappearance, and increased their bacterial phagocytic ability. Consequently, piperine administration conferred mice resistance against bacterial infection and even sepsis. Our data highlight that piperine has the capacity to metabolically reprogram peritoneal resident macrophages to fortify their innate functions against bacterial infection.

\section{INTRODUCTION}

Pepper has long been used as a food seasoning and an ingredient in folk medicine. Modern medicinal chemistry has revealed that piperine is the major plant alkaloid in pepper. This alkaloid possesses a broad spectrum of pharmacological activities, including antidepression and anti-epilepsy effects $[1,2]$, as well as abilities to reduce lipid deposition and body weight [3]. It is also effective for a variety of experimental inflammatory diseases, including gastric ulcer [4], arthritis [5], and endotoxin-induced shock [6]. In Asian countries, pepper is broadly used as a medicinal herb for treating gastrointestinal diseases [7], in which piperine might act as the major active component. Therefore, piperine appears to be a potential immunomodulator for therapeutic usage against inflammatory diseases as well as bacterial infection. However, the relationship between the metabolic and pharmacologic effects of piperine is unclear; particularly, the underlying action mechanism of piperine in the setting of bacterial infection is largely unknown.

Considering that pepper acts as a seasoning in improving digestion and appetite, we have tried to test influences of its major component piperine on a variety 
of signaling pathways of cellular metabolism. One of these pathways is the mTOR signaling. mTOR is a highly conservative molecule in eukaryotic evolution, which is necessary for maintaining metabolic homeostasis, cell proliferation, survival, and promoting protein synthesis [8, 9]. By binding with other proteins, mTOR forms two different large complexes, mTOR complex 1 (mTORC1) and mTORC2, which show different serine/ threonine kinase activities on their respective substrates. mTORC1 phosphorylates 4E-BP1 and p70S6K, while mTORC2 phosphorylates AKT at Ser473 [10]. In recent years, increasing studies have focused on the immunoregulatory function of mTOR signaling. For example, mTOR inhibitors have been reported to regulate immune responses, mainly serving as immunosuppressive agents $[11,12]$. On the other hand, emerging evidence demonstrates that uptake of amino acids and hence activation of mTOR are required for gastrointestinal homeostasis against invasion of commensal microbes [13], suggesting mTOR's action on promoting innate immunity of the gut.

Peritoneal macrophages (pMФs) are one type of tissue-resident macrophages that have been extensively explored, but their tissue-specific function has been poorly understood. One recent finding reveals that resident pMФs are pivotal innate immune cells in maintaining gastrointestinal homeostasis [14]. At homeostasis, resident pMФs are mainly composed of two populations: the large peritoneal macrophages (LPMs) with an F4/80 ${ }^{\text {hi }} \mathrm{MHCII}^{\text {low }}$ phenotype predominate the peritoneal cavity, while the small peritoneal macrophages (SPMs) with an F4/80 ${ }^{\text {low }} \mathrm{MHCII}^{\text {hi }}$ phenotype are the minor population. Although the developmental status of SPMs is largely unknown, the LPMs have been characterized as fetaloriginated tissue-resident macrophages expressing a distinctive transcription factor GATA6 [15, 16], and regulating the function of peritoneal B-1 cells [14]. Thus, resident $\mathrm{pM \Phi s}$ under the steady-state conditions constitute a differing population from monocyte-derived macrophages (MDMs) of the peritoneal cavity in the inflammatory settings.

Although piperine has been shown to suppress innate immune responses in inflammatory MDMs from the peritoneal cavity [6], it is still unknown whether piperine has similar effects on resident $\mathrm{pM} \Phi \mathrm{s}$ and whether its administration exacerbates or prevents peritoneal bacterial infection. In this study, we found that piperine potentiated the mTORC1 activity by recruiting system L1 amino acid transporter SLC7A5/SLC3A2 [17] to the cell membrane and promoting amino acid metabolism. Enhancement of the mTORC1 activity by piperine was correlated with reinforced functions of resident pMФs upon bacterial stimulation, which conferred mice resistance against peritoneal bacterial infection and sepsis. Our data highlight piperine as a pharmacological booster of the mTORC1 activity during amino acid metabolism to enhance the innate functions of resident $\mathrm{pM} \Phi \mathrm{s}$ against microbial infection.

\section{RESULTS}

\section{Piperine enhances the mTORC1 activity depending on amino acid metabolism}

The activity of piperine on the mTOR pathway was initially tested in cultured cell lines, and we discovered that piperine elevated the mTORC1 activity in human LNCaP and HeLa cells and mouse macrophage RAW 264.7 cells. Piperine treatment enhanced the phosphorylation of $4 \mathrm{E}$ BP1 and p70S6K, two substrates of the mTORC1 kinase, indicating that this alkaloid could enhance the mTORC1 signaling in these cell lines (Supplementary Figure S1, A, $\mathrm{B}$ and $\mathrm{C})$.

We next determined the action mechanism by which piperine enhanced the mTORC1 activity. mTOR is a central player in sensing nutrient sufficiency and regulating diverse metabolic processes [18]. It can be activated by hormones (e.g. insulin), nutrients, and cytokines [19]. Piperine has been shown to enhance the permeability of intestinal epithelial cells [20], increase the bioavailability of various drugs $[21,22]$ and promote the uptake of amino acids [20]. These studies prompted us to explore whether piperine enhanced the mTORC1 activity depending on nutrients in culture medium. To this end, HeLa cells were first starved in Earle's Balanced Salt Solution (EBSS) medium (without serum and amino acids) to suppress the basal mTORC1 activity, and then cultured in different media lacking serum, amino acids or glucose, respectively. The mTORC1 failed to be activated by EBSS medium, either with or without glucose. In contrast, the mTORC1 activity was elevated by serumfree DMEM, and was further potentiated by piperine cotreatment (Figure 1A and 1B).

Considering that DMEM contains amino acids but EBSS does not, these results suggested that piperineinduced elevation of the $\mathrm{mTORC} 1$ activity may rely on the presence of amino acids, instead of glucose. It is known that mTORC1 is activated during glutaminolysis, in which L-glutamine (Gln) is sequentially metabolized into L-glutamate and $\alpha$-keroglutarate by glutaminase and glutamate dehydrogenase, respectively [23]. As an allosteric activator of glutamate dehydrogenase, L-leucine (Leu) promotes the conversion of L-glutamate to $\alpha$-keroglutarate, which is a robust inducer of $\mathrm{mTORC} 1$ activation [24]. However, Gln is the rate-limiting amino acid for the mTORC1 activation by this way, since the efflux of intracellular Gln is required for the uptake of Leu and other essential amino acids via the bidirectional SLC7A5/SLC3A2 transporter [25]. Consistent with these studies, the mTORC1 activity was activated in HeLa 
cells in the presence of Leu, or Leu plus Gln, but not Gln alone, and combination of these amino acids with piperine further increased the mTORC1 activity (Figure 1C and 1D and Supplementary Figure S2A). Notably, after the cells were starved for a short period (50 min), which is likely insufficient to exhaust the intracellular Gln pool [23], piperine potentiated the $\mathrm{mTORC} 1$ activation induced by Leu treatment alone at $30 \mathrm{~min}$ (Figure 1C and 1D), but not at $2 \mathrm{~h}$ (Supplementary Figure S2A). Moreover, when Gln was preloaded into the cells having starved for $3 \mathrm{~h}$, piperine markedly intensified Leu-induced mTORC1 activation at time point of $30 \mathrm{~min}$ (Figure $1 \mathrm{E}$ and $1 \mathrm{~F}$ ), and also enhanced it at earlier (Supplementary Figure S2B) or later time points (Figure 1E and 1F). Collectively, piperine-induced elevation of the mTORC1 activity relies on the uptake of specific (or essential) amino acids including Leu in the presence of intracellular Gln.

\section{Piperine enhances mTORC1 activity by recruiting amino acid transporters to the cell surface}

SLC7A5/SLC3A2 heterodimer is also known as system L1 amino acid transporter, the major cell surface transporter for Leu [17]. This is a bidirectional transporter as the export of Gln is required for the import of Leu [25], which can critically activates the mTORC1 activity $[18,25]$. We explored whether the effect of piperine on mTORC1 activation was contributed by this bidirectional transporter. Consistent with previous reports [25], our
A

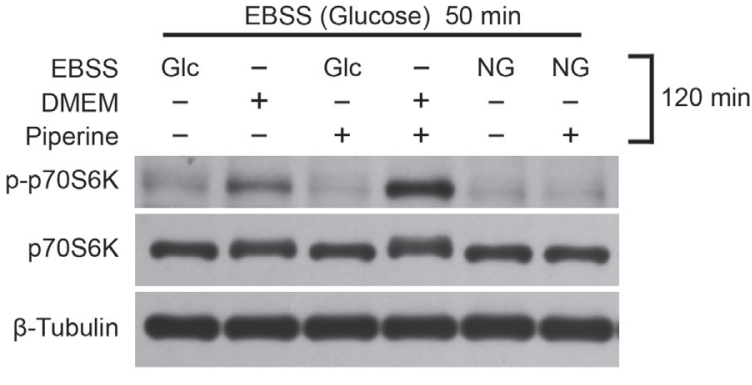

B

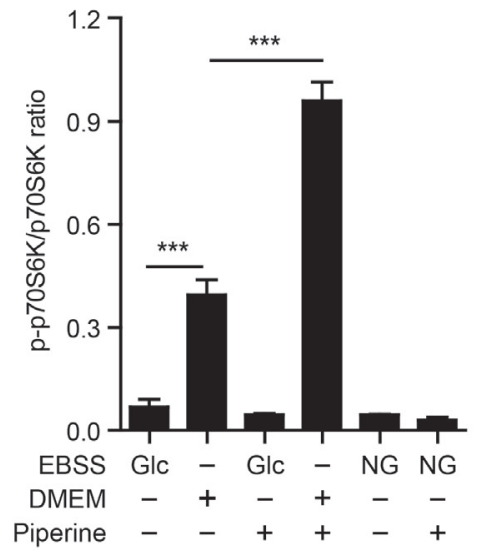

C

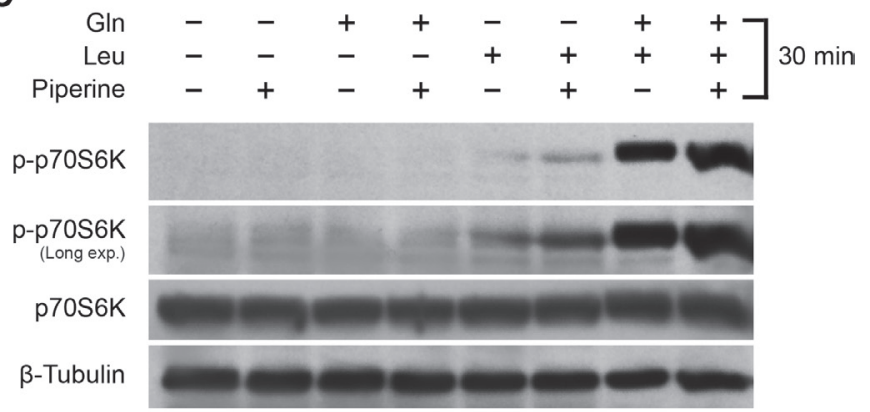

D

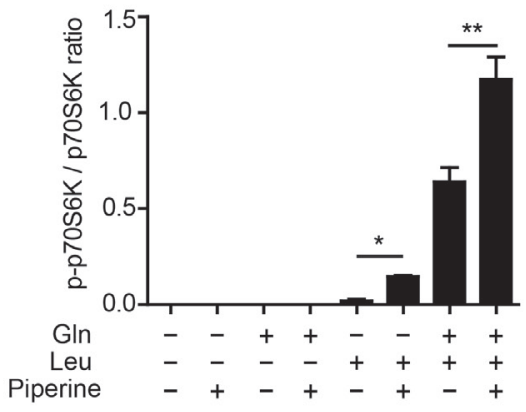

$\mathbf{F}$

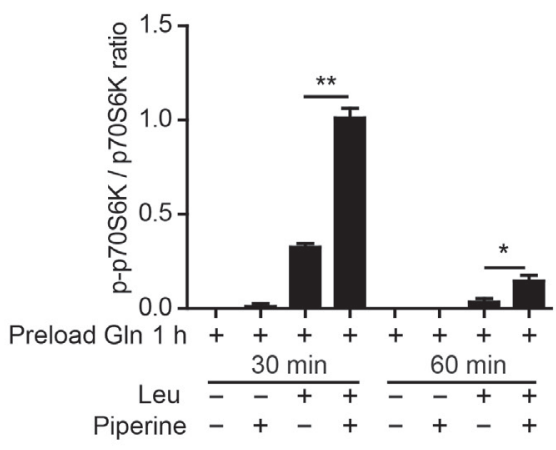

Figure 1: Piperine enhances mTORC1 activation in the presence of amino acids. A.-F. Western blotting showing p-p70S6K levels in HeLa cells that were first starved in Earle's Balanced Salt Solution (EBSS, with glucose) for 50 min A. or Krebs-Ringer bicarbonate buffer (KRBB) for $50 \mathrm{~min}$ C. or KRBB for $3 \mathrm{~h} \mathrm{E}$., followed by incubation in indicated media (serum-free) for indicated time periods. Gln (L-glutamine, $2 \mathrm{mM}$ ), Leu (L-leucine, $0.8 \mathrm{mM})$ and/or piperine $(40 \mu \mathrm{M})$ were added in EBSS A. or KRBB C., E.. Glc, glucose; NG, no glucose. Quantification of p-p70S6K relative to total p70S6K is shown in B., D. and F. $(n=3)$. The significance was analyzed by Student's $t$-test. $* P<0.05 ; * * P<0.01 ; * * * P<0.001$. 
result showed that knockdown of SCL7A5 with siRNA also downregulated the expression of SLC3A2 (Figure $2 \mathrm{~A}$ and 2B). As expected, the effect of piperine on enhancing Leu-induced mTORC1 activation (as revealed by $\mathrm{p} 70 \mathrm{~S} 6 \mathrm{~K}$ phosphorylation) was greatly suppressed by SLC7A5 knockdown (Figure 2A and 2B). Likewise, immunofluorescence microscopy demonstrated that Leu induced the co-localization of mTOR and lysosome marker LAMP2, indicating the activation of mTOR on the lysosomal membrane. Once again, piperine
A

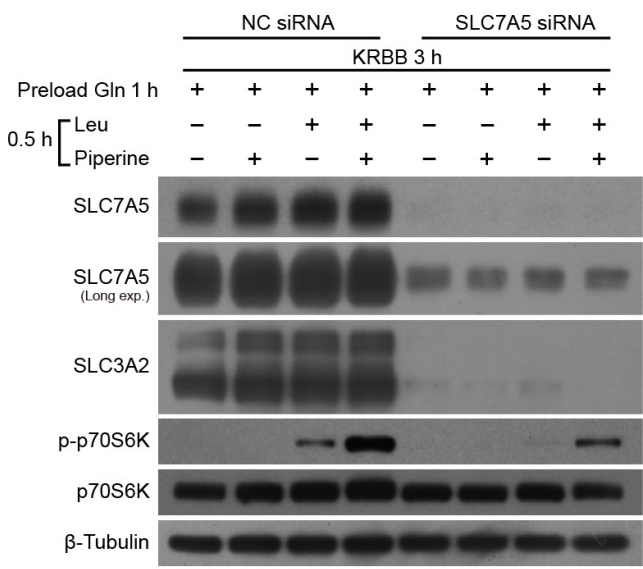

B

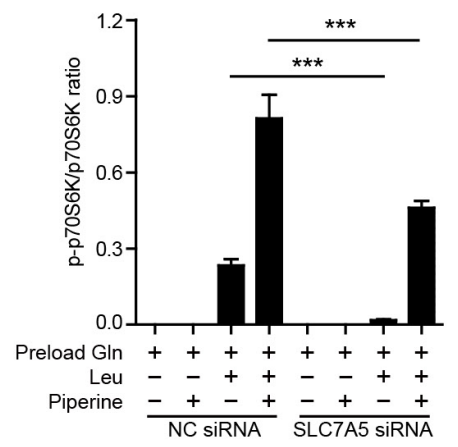

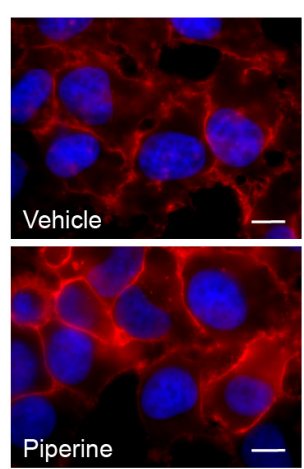

C

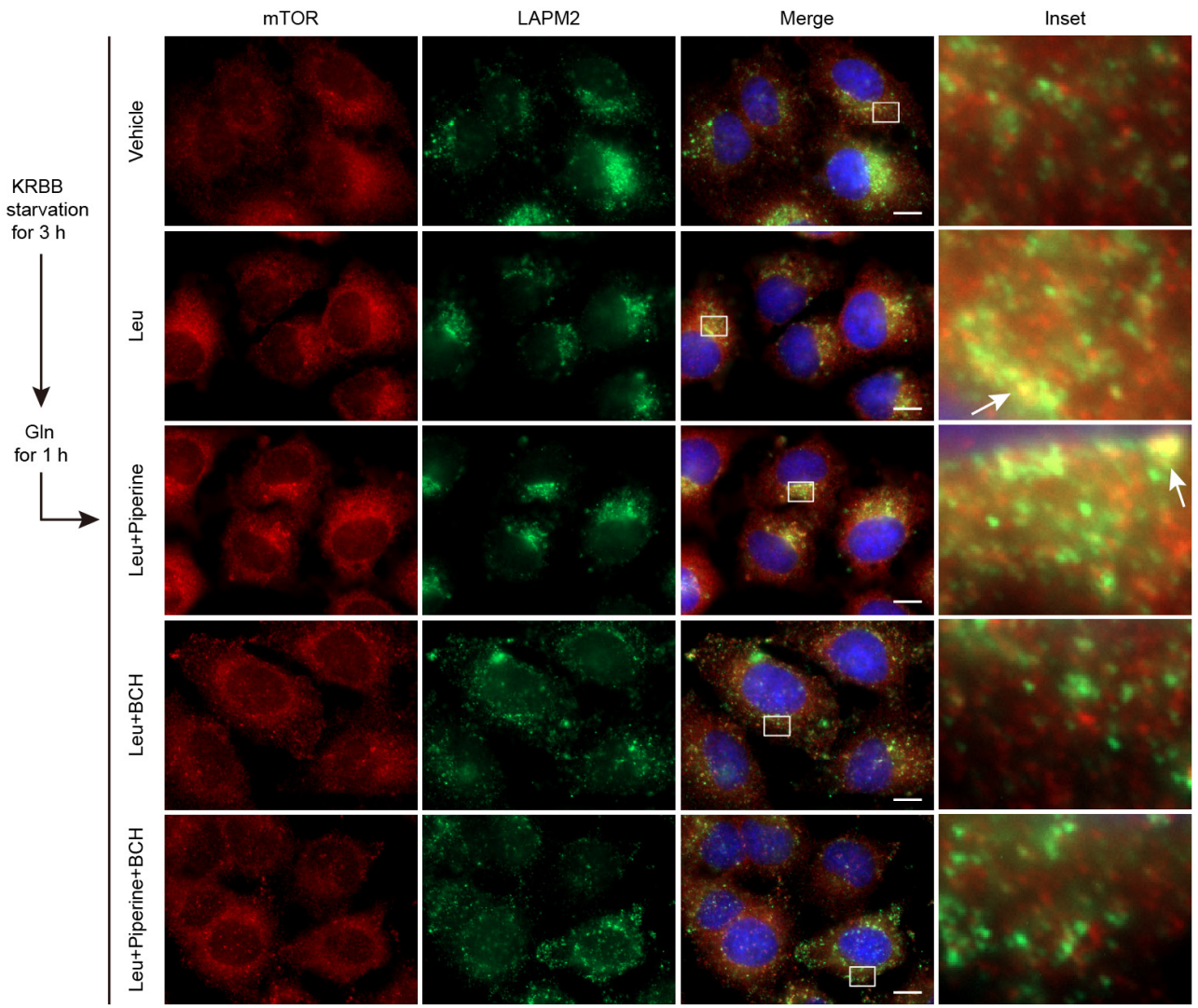

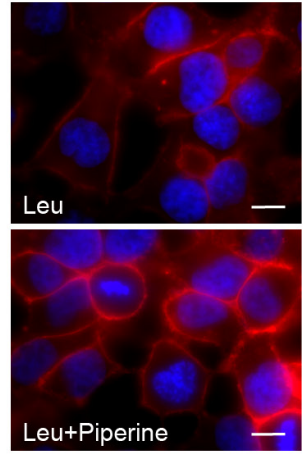

E

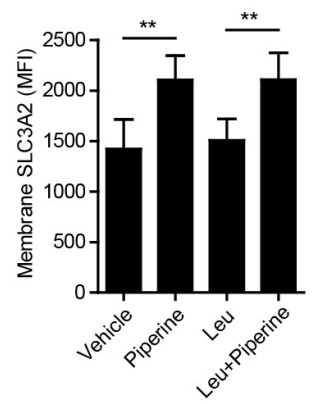

Figure 2: Piperine enhances Leu-induced mTOR activation through amino acid transporter. A. SLC7A5 protein expression in HeLa cells was first knocked down with specific siRNA or negative control siRNA for $72 \mathrm{~h}$. Afterwards, the cells were starved in KRBB and then sequentially loaded with $\mathrm{Gln}(2 \mathrm{mM})$, Leu $(0.8 \mathrm{mM})$ and/or piperine $(40 \mu \mathrm{M})$ for indicated periods. Western blotting was used to detect protein expression levels. The quantification of p-p70S6K relative to total p70S6K in A. is shown in B. as mean $\pm \mathrm{SD}(n=3)$. C. HeLa cells were first starved in KRBB and then sequentially loaded with Gln for $1 \mathrm{~h}$, and Leu and/or piperine for $0.5 \mathrm{~h}$. SLC7A5/SLC3A2 activity was inhibited by BCH $(50 \mathrm{mM})$. Subcellular mTOR and LAMP2 distribution were revealed by immunofluorescence microscopy. Arrows indicate typical co-localization of mTOR and LAMP2 (yellow puncta). The nuclei (blue) were revealed by Hoechst33342 staining. D. HeLa cells were treated as $\mathbf{C}$. and the subcellular distribution of SLC3A2 was revealed by immunofluorescence microscopy. E. Cell membranous SLC3A2 distribution was evaluated by its mean fluorescence intensity (MFI) ( $n=10$ fields). Scale bars, $10 \mu \mathrm{m}$. The significance was estimated by Student's $t$-test. ** $P<0.01 ; * * * P<0.001$. 
treatment enhanced Leu-induced mTOR activation by promoting the translocation of mTOR onto the lysosome. However, when Leu transporter was blocked by 2-amino2-norbornanecarboxylic acid $(\mathrm{BCH})$, an inhibitor of SLC7A5 [25, 26], the co-localization of mTOR and LAMP2 was abrogated (Figure 2C). These results suggested that piperine enhanced Leu-induced mTORC1 activation through the system L1 amino acid transporter SLC7A5/SLC3A2. To further verify this hypothesis, the subcellular distribution of SLC7A5/SLC3A2 was observed by immunofluorescence microscopy analysis of the SLC3A2 subunit. The results showed that SLC3A2 was distributed at both cell membrane and intracellular compartments in vehicle-treated cells. After piperine treatment, regardless of the presence or absence of Leu, more SLC3A2 was distributed at the cell membrane, with increased mean fluorescent intensity (MFI) in this cellular compartment. However, the difference on cellmembranous MFI between vehicle and Leu groups was not statistically significant (Figure 2D and 2E). Thus, piperine appeared to poise cells to transport amino acids more efficiently by recruiting intracellular SLC7A5/ SLC3A2 onto the cell membrane.

\section{Piperine treatment activates mTORC1 signaling in resident $\mathbf{p M \Phi s}$}

To confirm whether piperine potentiates mTORC1 activity in primary macrophages, we treated freshly isolated mouse resident $\mathrm{pM} \Phi \mathrm{s}$ with piperine and measured the phosphorylation levels of p70S6K by Western blotting. Piperine significantly increased the phosphorylation levels of p70S6K, which could be attenuated by LY294002, an inhibitor of PI3K upstream of mTORC1 [27] (Figure 3A and $3 \mathrm{~B}$ ). Furthermore, immunofluorescence microscopy revealed that piperine time-dependently elevated the phosphorylation of S6 protein, a substrate of p70S6K, in $\mathrm{CD}_{11} \mathrm{~b}^{+}$resident pMФs (Figure $3 \mathrm{C}$ and $3 \mathrm{D}$ ). When resident $\mathrm{p} М \Phi \mathrm{s}$ were preloaded with Gln after amino acid starvation for $3 \mathrm{~h}$, piperine greatly enhanced mTORC1 activation in the presence of Leu (Figure $3 \mathrm{E}$ and $3 \mathrm{~F}$ ). Thus, piperine elevated the mTORC1 activity both in RAW 264.7 macrophage cell line and in primary resident pMФs.
A

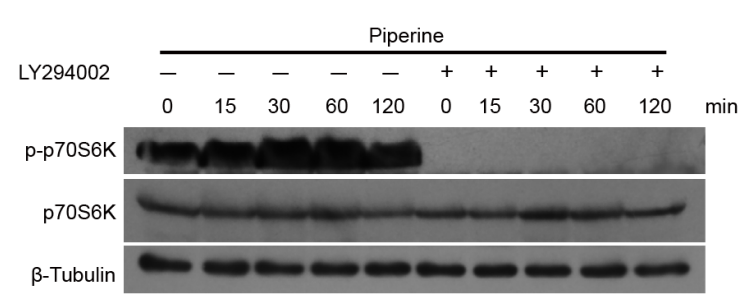

B

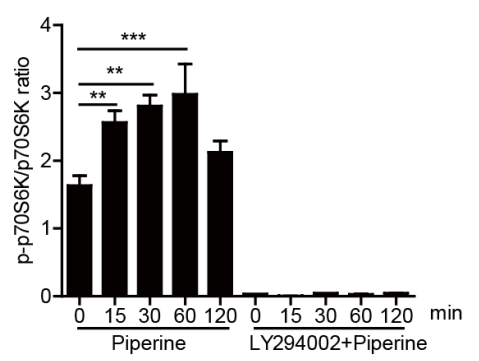

C

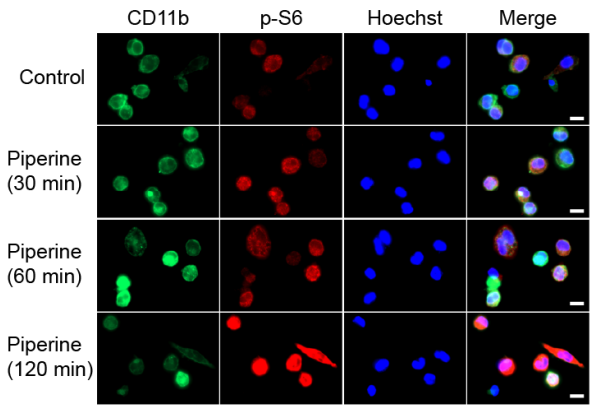

D

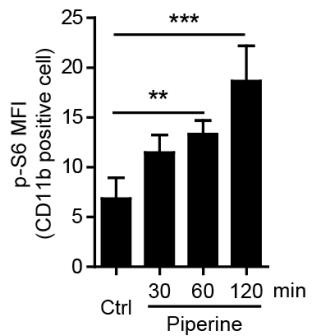

$\mathbf{F}$

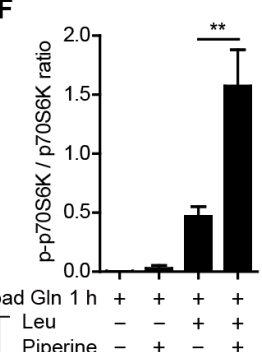

Figure 3: Piperine enhanced mTORC1 activation in mouse peritoneal resident macrophages. A. Western blot analysis showing that piperine $(40 \mu \mathrm{M})$ elevated the phosphorylation levels of p70S6K in mouse peritoneal resident macrophages, which was suppressed by LY294002 $(10 \mu \mathrm{M})$ pretreatment. The quantification of p-p70S6K relative to total p70S6K in A. is shown in B. $(n=3)$. C. Immunofluorescence microscopy showing mTORC1 activity by the intracellular p-S6 levels (red) in CD11b (green) macrophages upon piperine exposure. The nuclei (blue) were revealed by Hoechst33342 staining. Scale bars, $10 \mu \mathrm{m}$. D. Quantitative analysis of p-S6 mean fluorescence intensity (MFI) in C. ( $n=10$ fields). E. and F. Freshly isolated mouse peritoneal resident macrophages were starved in KRBB. Then the cells were preloaded with Gln, followed by piperine and Leu co-treatment as did in Figure 1E. The mTORC1 activation was detected by Western blotting E. and the quantification of p-p70S6K relative to total p70S6K is shown in $\mathbf{F}$. $(n=3)$. The significance was estimated by Student's $t$-test. $* * P<0.01 ; * * * P<0.001$. 
Piperine treatment increases LPS-stimulated IL-6 and TNF- $\alpha$ expression in resident $\mathrm{pM \Phi s,} \mathrm{but} \mathrm{not}$ in thioglycollate (TG)-elicited ones

Although piperine has exhibited anti-inflammatory activity in different models [4-6], its effect on cytokine expression in resident $\mathrm{pM} \Phi \mathrm{s}$ has not yet been evaluated. As enhanced mTOR activity can promote global protein synthesis [8-10] and increase IL-6 and TNF- $\alpha$ secretion in $\beta$-glucan-trained macrophages [28], we sought to explore whether piperine, which acted as a booster of MTORC1 activation, elevated the expression of these cytokines in resident $\mathrm{pM} \Phi \mathrm{s}$. Indeed, piperine pretreatment for either short periods $(1 \mathrm{~h}$ and $6 \mathrm{~h})$ or a prolonged period $(48 \mathrm{~h})$ markedly enhanced IL- 6 and TNF- $\alpha$ production from resident $\mathrm{pM \Phi s} \mathrm{stimulated} \mathrm{with} \mathrm{LPS,} \mathrm{while} \mathrm{piperine} \mathrm{alone}$ had minimal effect (Figure 4A, 4B and 4C). Moreover, in response to LPS stimulation in vitro, resident $\mathrm{pM} \Phi \mathrm{s}$ isolated from C57BL/6 mice which had intragastrically (i.g.) administered with piperine for 10 days produced more than two-fold amounts of IL- 6 and TNF- $\alpha$ as much as that of their counterparts from vehicle-treated mice. But without LPS stimulation, the expression of these cytokines was low in the pMФs isolated from both piperineconditioned and control mice (Figure 4D).

However, when thioglycollate (TG)-elicited pMФs were used for experiments, piperine pretreatment did not change IL- 6 and TNF- $\alpha$ expression upon LPS stimulation (Supplementary Figure S3A), but even suppressed the expression of interferon- $\gamma$ (Supplementary Figure S3B), in step with a previous study [6]. As aforementioned, pMФs may be classified into two populations based on their expression of macrophage markers F4/80 and MHC class II (MHCII) molecules [14]. The differential responses of cytokine expression in resident $\mathrm{p} М \Phi s$ and TG-elicited ones is likely because they are different types of macrophages, with the latter being mostly MDMs as a result of TG stimulation.

To confirm this, we analyzed the phenotypes of these two macrophage populations by flow cytometry. TG treatment suppressed the expression of F4/80 in the $\mathrm{pM} \Phi \mathrm{s}$, while the resident $\mathrm{pM} \Phi \mathrm{s}$ in control group contained more LPMs but fewer SPMs as compared to TG-elicited cells (Supplementary Figure S4A). Moreover, GATA6, a transcription factor critical for resident $\mathrm{pM} \Phi$ function and survival [16], was highly expressed in resident $\mathrm{pM \Phi s,} \mathrm{but} \mathrm{only} \mathrm{in} \mathrm{a} \mathrm{minor} \mathrm{subset} \mathrm{of} \mathrm{TG-elicited}$ cells (Supplementary Figure S4A and S4B). In addition, TG-elicited $\mathrm{pM} \Phi \mathrm{s}$ were, on average, larger in size than the resident ones (Supplementary Figure S4B). Therefore, the resident and TG-elicited $\mathrm{pM} \Phi \mathrm{s}$ were composed of different cell populations, thus representing different types of macrophages, which may probably account for their
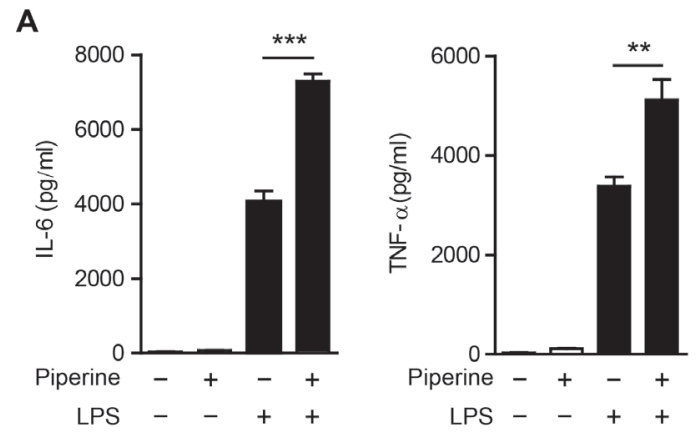

B
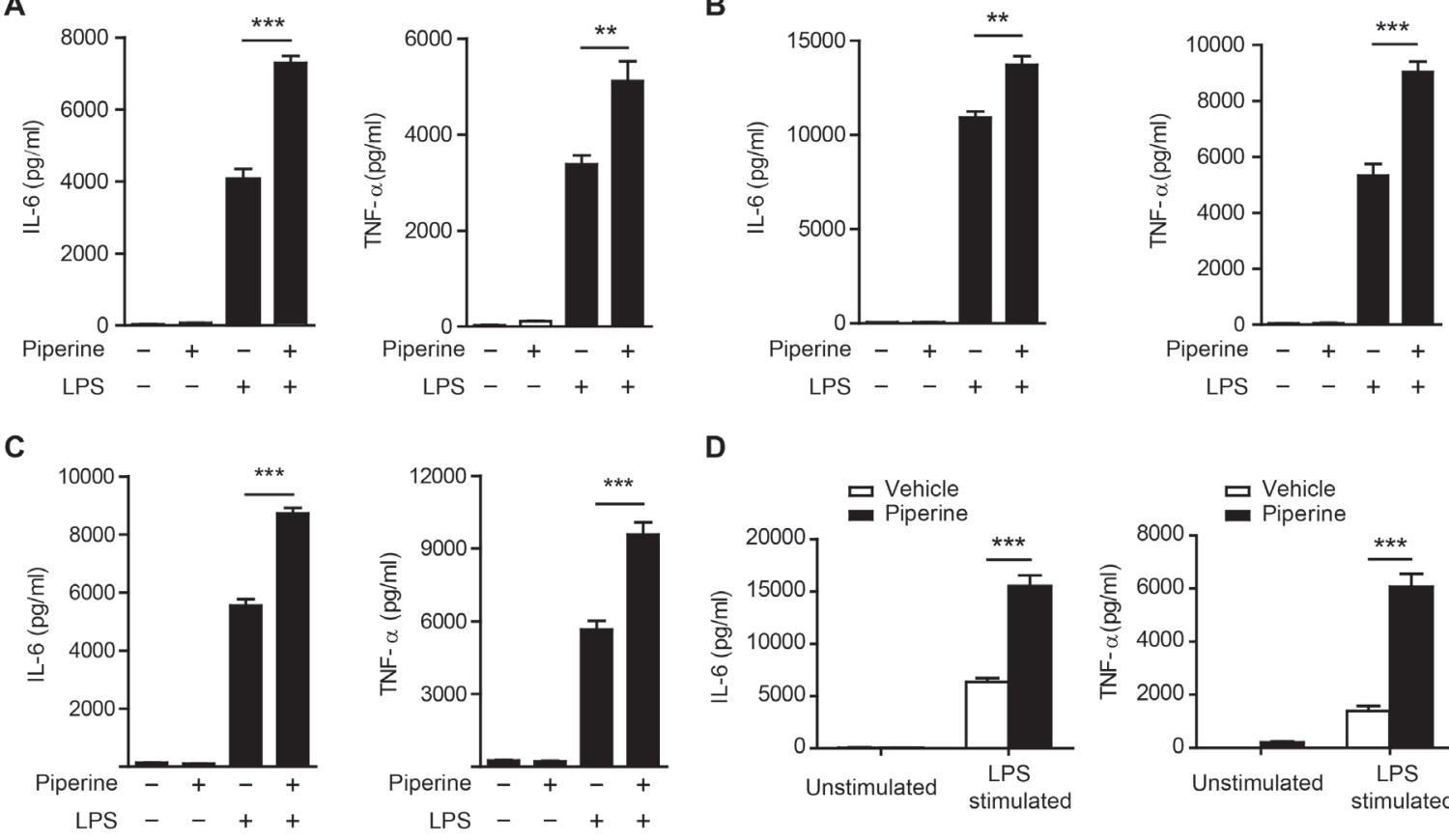

D
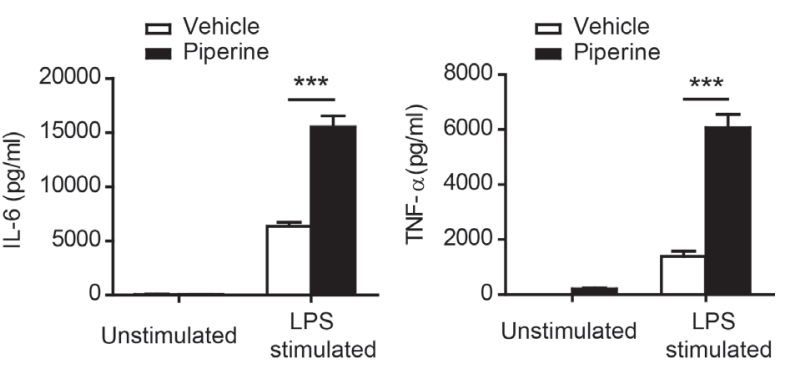

Figure 4: Piperine enhances cytokine expression in peritoneal resident macrophages upon LPS stimulation in vitro. A.-C., Mouse peritoneal resident macrophages were pretreated with or without piperine for $1 \mathrm{~h} \mathrm{A.,} 6 \mathrm{~h} \mathrm{~B}$., or $48 \mathrm{~h} \mathrm{C}$., followed by LPS $(100 \mathrm{ng} / \mathrm{ml})$ stimulation for $24 \mathrm{~h}$. D. C57BL/6 mice were administered with piperine $(20 \mathrm{mg} / \mathrm{kg})$ or vehicle via gavage once a day for 10 consecutive days and their peritoneal resident macrophages were isolated, cultured in vitro, and stimulated with $100 \mathrm{ng} / \mathrm{ml} \mathrm{LPS}$ for 24 h. Cytokines in the culture media were measured. All experiments were repeated for three times independently with one representative experiment presented in A., B. and C. (mean $\pm \mathrm{SD}, n=3$ ) and in D. (mean $\pm \mathrm{SD}, n=5$ mice). The significance was analyzed by Student's $t$-test. ${ }^{* *} P<0.01 ; * * * P<0.001$. 
differential patterns of cytokine expression upon piperine treatment.

\section{Piperine-induced enhancement of cytokine production is abrogated by $\mathrm{PI} 3 \mathrm{~K} / \mathrm{AKT} / \mathrm{mTOR}$ pathway inhibitors}

As the above data indicated that piperine elevated the mTORC1 activity concomitant with enhanced cytokine expression in resident $\mathrm{pM} \Phi \mathrm{s}$, we next explored the causality between these two processes by blocking

A

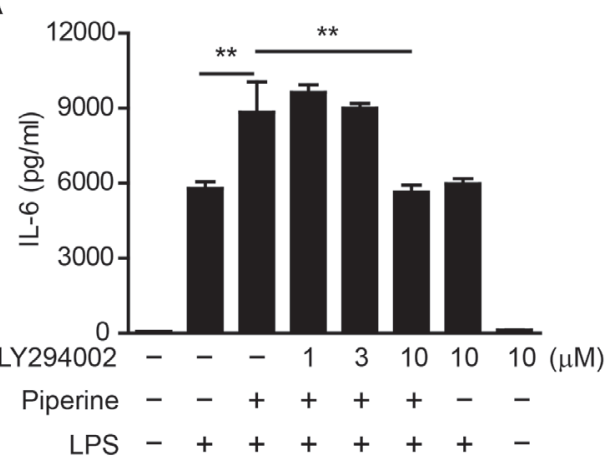

B

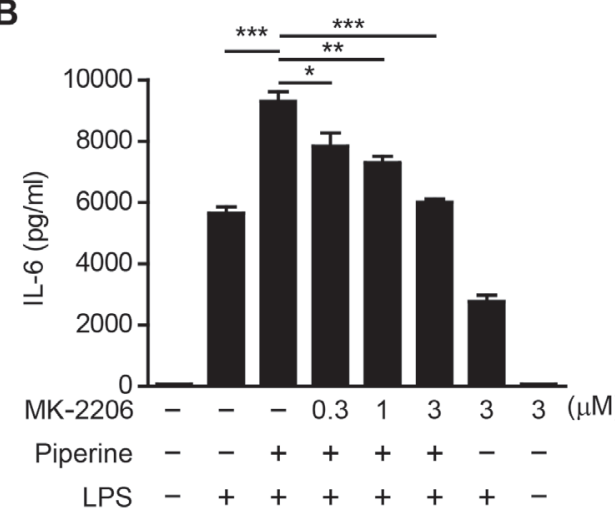

C

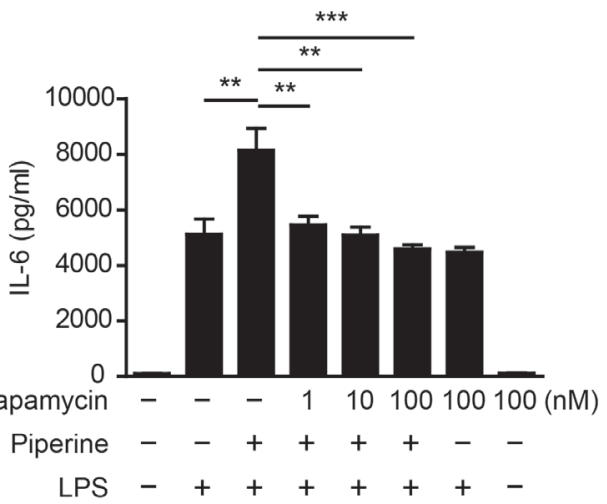

mTOR activation during piperine treatment. Both indirect mTORC1 inhibitors LY294002 (PI3K inhibitor) [27] and MK-2206 (AKT inhibitor) [29], and direct inhibitor rapamycin [30], completely abrogated the enhancement of IL- 6 and TNF- $\alpha$ expression in the presence of piperine. However, they had minimal effect on LPS-induced cytokine expression except MK-2206's effect on IL-6 expression (Figure 5A, 5B and 5C). These results indicated that piperine increased IL- 6 and TNF- $\alpha$ protein expression by enhancing the mTOR signaling.
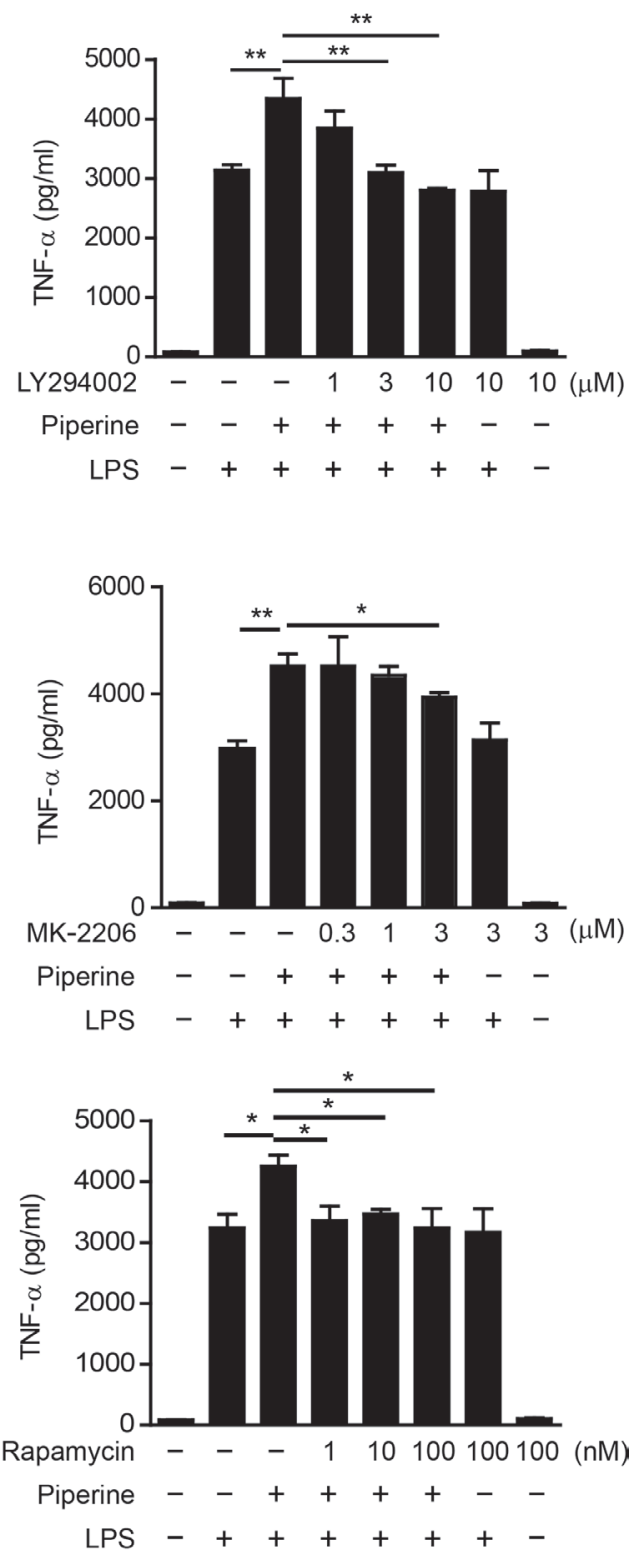

Figure 5: Piperine enhances IL-6 and TNF- $\alpha$ expression in peritoneal resident macrophages in an mTOR-dependent manner. Isolated mouse peritoneal resident macrophages were pretreated with indicated concentrations of PI3K inhibitor LY294002, AKT inhibitor MK-2206 or mTOR inhibitor rapamycin for $30 \mathrm{~min}$. Piperine $(40 \mu \mathrm{M})$ were added to the media for $1 \mathrm{~h}$ and the cells were stimulated with $100 \mathrm{ng} / \mathrm{ml}$ LPS for $24 \mathrm{~h}$. Cytokines in culture media were measured. All experiments were repeated for three times independently with one representative experiment presented in $\mathbf{A}$., B. and $\mathbf{C}$. (mean $\pm \mathrm{SD}, n=3)$. The significance was estimated by oneway ANOVA followed by Tukey's multiple comparison test. $* P<0.05 ; * * P<0.01 ; * * * P<0.001$. 


\section{Piperine administration provides protection against bacterial infection and sepsis}

As IL-6 and TNF- $\alpha$ are critical for pathogen clearance by enhancing the functions of phagocytes [31, 32] and by promoting the expression of antimicrobial peptides [33], we next further assessed whether enhanced IL- 6 and TNF- $\alpha$ production in resident pMФs of mice having administered with piperine conferred resistance to bacterial infection and septic shock. To verify this, C57BL/6 mice were infected with lethal or sub-lethal doses of viable Escherichia coli, and piperine was administered before (prophylactic model) or after (therapeutic model) bacterial inoculation. The results showed that piperine treatment significantly protected mice against lethal bacterial infection either in the prophylactic (Figure 6A) or therapeutic model (Figure

\section{A}

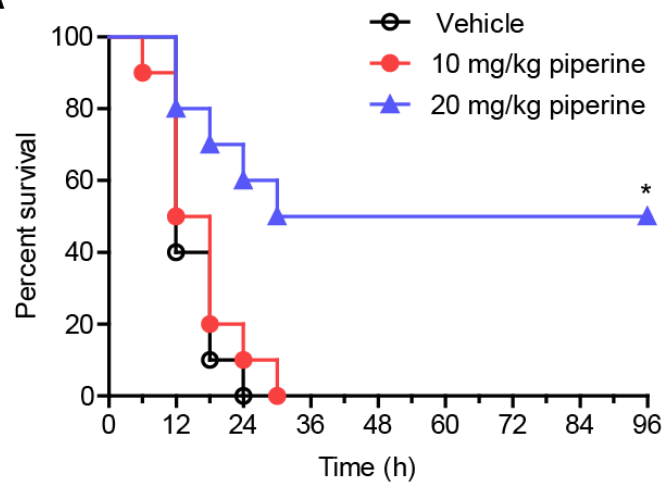

B

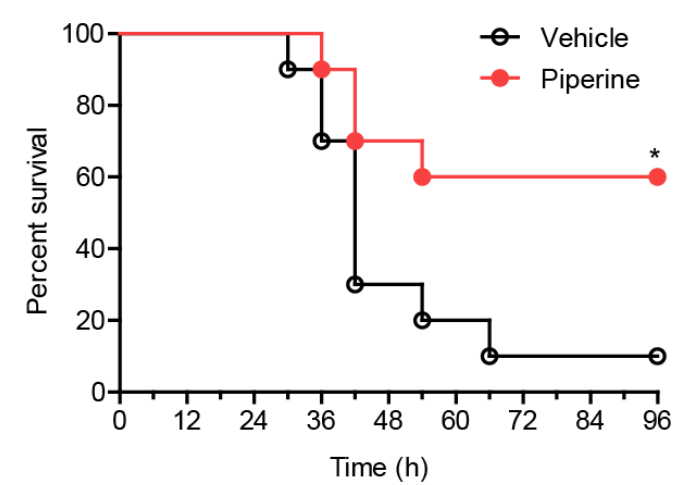

D

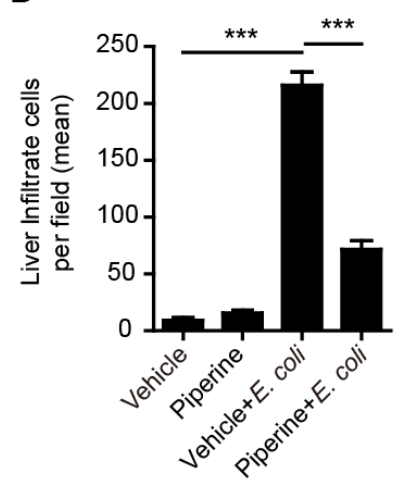

$\mathrm{F}$

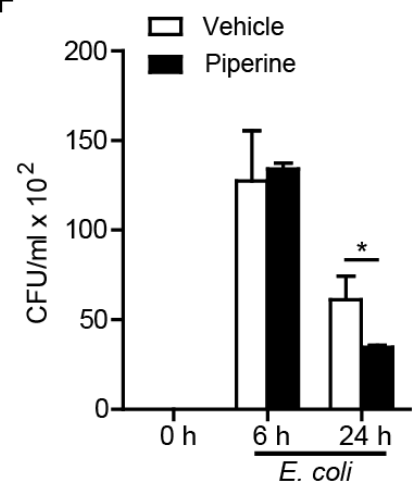

Figure 6: Piperine administration confers resistance to bacterial infection and attenuates sepsis. $A$. and B. Survival of C57BL/6 mice infected with viable E. coli. Mice ( $n=10$ for each group) were administered with piperine intragastrically prior to A. or after (B.; piperine $20 \mathrm{mg} / \mathrm{kg}$ ) bacterial inoculation as described in Methods. The significance was evaluated by the nonparametric MannWhitney $U$ test. $* P<0.05$. C. Representative haemotoxylin and eosin staining of the liver and colon $8 \mathrm{~h}$ after infection from C57BL/6 mice ( $n=5$ for each group) treated as in A.. D. Quantification of infiltrate cells in the liver. (E and F) IL-6 and TNF- $\alpha$ E. and bacterial counts F. in the peritoneal cavity of E. coli-infected mice. C57BL/6 mice (C-F) were treated with or without piperine $(20 \mathrm{mg} / \mathrm{kg})$ as in A., followed by $E$. coli $\left(1 \times 10^{9} \mathrm{CFU} /\right.$ mouse $)$ infection. The experiments were repeated for three times independently with one representative experiment presented (mean $\pm \mathrm{SD}, n=5$ ). Bacterial counts were measured by LB agar culture $\mathbf{F}$.. The significance was estimated by Student's $t$-test. $* P<0.05 ; * * P<0.01 ; * * * P<0.001$. 
$6 \mathrm{~B})$. For the prophylactic model, the control mice that were infected with a lethal dose of viable $E$. coli $\left(2 \times 10^{9}\right.$ $\mathrm{CFU} / \mathrm{mouse}$ ) into their peritoneal cavity died within $24 \mathrm{~h}$, but those having administered with piperine had higher survival rates after bacterial infection. Among the mice having treated with $20 \mathrm{mg} / \mathrm{kg}$ but not $10 \mathrm{mg} / \mathrm{kg}$ piperine, $60 \%$ survived the first $24 \mathrm{~h}$ after bacterial challenge and $50 \%$ were still alive in an active state after $96 \mathrm{~h}(P<$ 0.05 ; Figure $6 \mathrm{~A})$. In the therapeutic model, piperine (20 $\mathrm{mg} / \mathrm{kg}$ ) treatment $1 \mathrm{~h}$ after bacterial infection with a sublethal dose of $E$. coli $\left(1 \times 10^{9} \mathrm{CFU} /\right.$ mouse $)$ also reduced the mouse mortality $(P<0.05$; Figure 6B). Histochemical analysis demonstrated that viable bacterial infection in the peritoneal cavity had induced sepsis, but the symptoms of sepsis were alleviated by piperine treatment, with fewer infiltrated leukocytes in the liver tissue sections and no obvious inflammation in the colon (Figure 6C and 6D).

As expected, bacterial infection greatly increased the expression of IL- 6 and TNF- $\alpha$ in their peritoneal cavity, whereas such cytokine levels were lower or undetectable without bacterial infection. Interestingly, compared with controls, piperine-administered mice had significant higher IL- 6 and TNF- $\alpha$ levels in their peritoneal cavity lavage fluids at $6 \mathrm{~h}$ but had lowered levels of these cytokines at $24 \mathrm{~h}$ (Figure 6E) after bacterial infection, accompanied with a declined bacterial burden at $24 \mathrm{~h}$ (Figure 6F). Therefore, piperine administration to mice appeared to enhance the innate functions of their pMФs, thereby accelerating bacterial clearance and inflammation resolution in their peritoneal cavity.
A

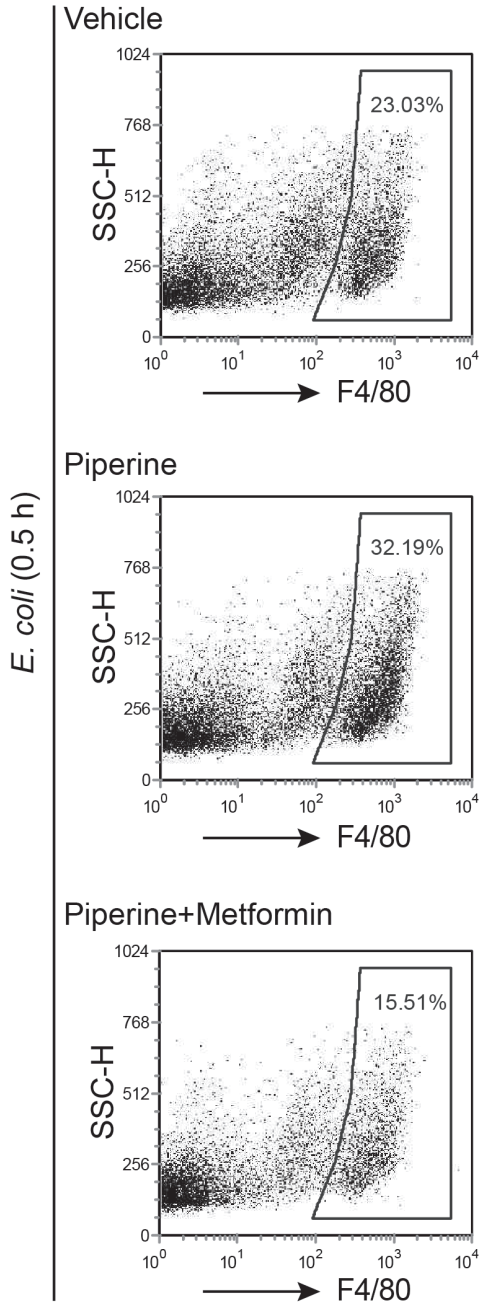

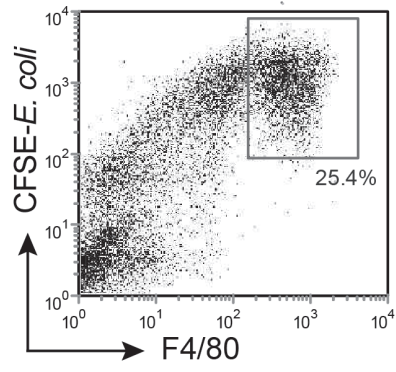
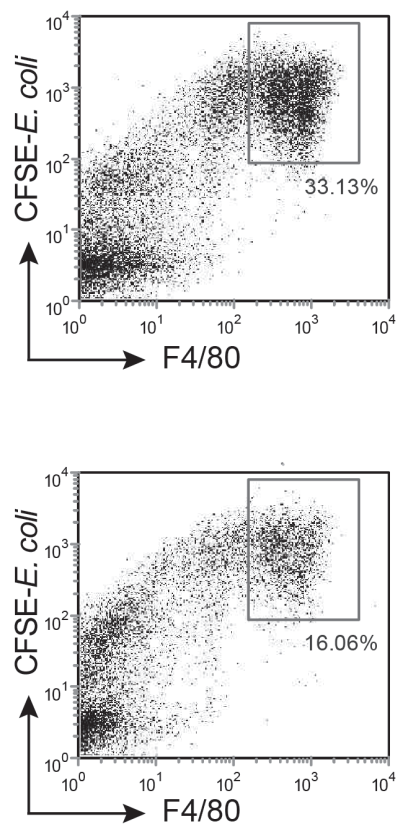

B
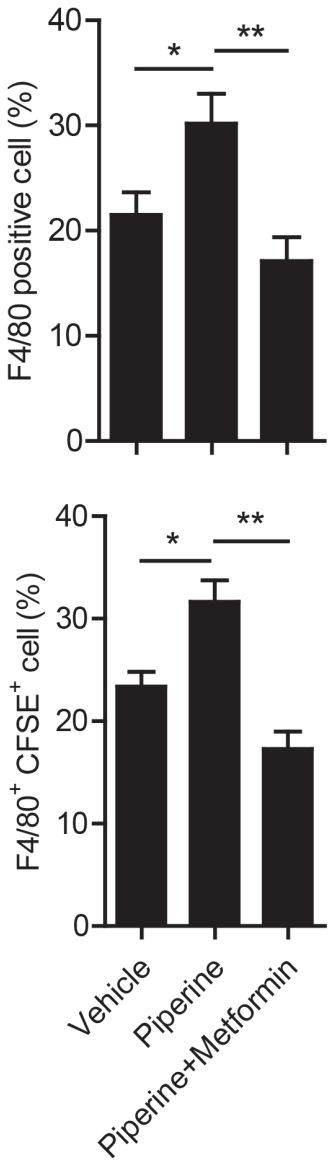

Figure 7: Resident pMФs from piperine-treated mice exhibits increased capacity to phagocytize bacteria. A. Mice were administered with piperine $(20 \mathrm{mg} / \mathrm{kg})$ or piperine plus metformin $(250 \mathrm{mg} / \mathrm{kg})$ intragastrically once and $4 \mathrm{~h}$ later were injected with CFSElabeled E. coli (equivalent to $0.5 \times 10^{9} \mathrm{CFU}$ viable bacteria/mouse) intraperitoneally for $0.5 \mathrm{~h}$. Afterwards, the peritoneal cells were isolated and stained with F4/80 antibody and analyzed by flow cytometry. Data were from one representative set of 3 independent experiments. B. Quantitative analyses of percentages of $\mathrm{F} 4 / 80^{+}$macrophages and percentages of $\mathrm{F} 4 / 80^{+} \mathrm{CFSE}^{+}$cells in gated cells. Data are expressed as mean $\pm \mathrm{SD}(n=5)$. The significance was estimated by one-way ANOVA followed by Tukey's multiple comparison test. $* * P<0.01 ; * * * P$ $<0.001$. 


\section{Piperine protects resident pMФs from bacterium- induced apoptosis}

The lowered bacterial burden in piperineadministered mice prompted us to explore whether piperine treatment had enhanced the bacterial phagocytic ability of their resident $\mathrm{pM} \Phi$ s. For this purpose, mice were injected with CFSE-labeled bacteria and their resident pMФs were analyzed by flow cytometry. The results showed that most $\mathrm{F} 4 / 80^{\text {hi }}$ cells also had highest CFSE intensity (Figure 7A), suggesting that the $\mathrm{F} 4 / 80^{\text {hi }}$ resident pMФs were the major bacterial phagocytic cells at the early stage of infection, which is in step with previous reports [34]. It was noticeable that the ratio of $\mathrm{F} 4 / 80^{\mathrm{hi}}$ resident $\mathrm{pM} \Phi \mathrm{s}$ in piperine-administered group was higher than that of control (vehicle group) (Figure 7), suggesting that piperine treatment protected the $\mathrm{F} 4 / 80^{\text {hi }}$ resident $\mathrm{pM} \Phi \mathrm{s}$ from bacterium-induced disappearance, a phenomenon having been observed in peritonitis decades ago [35]. However, co-treatment with metformin, an activator of AMPK and indirect inhibitor of mTOR signaling [28], greatly attenuated such an effect of piperine, reducing both the ratios of $\mathrm{F} 4 / 80^{\mathrm{hi}}$ and $\mathrm{F} 4 / 80^{\mathrm{hi}} \mathrm{CFSE}^{+} \mathrm{pM} \Phi \mathrm{s}$ (Figure 7).

These data indicated that fewer pMФs could be isolated from the peritoneal cavity of mice infected with bacteria as compared with control mice. Indeed, the F4/80 cells in normal mice accounted for about $80 \%$ of the total pMФs (Supplementary Figure 4A), but after infection this ratio could be reduced below $30 \%$ (Figure 7). It appeared that bacterial infection had quickly (within $0.5 \mathrm{~h}$ ) led to resident $\mathrm{pM} \Phi$ disappearing. However, piperine treatment seemed to attenuate the disappearance of $\mathrm{F} 4 / 80^{\text {hi }} \mathrm{pM \Phi s}$ by bacterial infection (Figure 7). Considering the effect of piperine on mTOR activation and the role of $\mathrm{mTOR}$ in cell survival [36], we explored whether piperine protected $\mathrm{F} 4 / 80^{\mathrm{hi}}$ resident $\mathrm{pM} \Phi \mathrm{s}$ from cell death. To this end, mice were infected with viable bacteria for $0.5 \mathrm{~h}$ and their pMФs were immediately isolated and seeded in glassbottom culture dishes, followed by CD11b and GATA6 antibody staining. It has been reported that GATA6 expression is a characteristic for resident $\mathrm{pM} \Phi \mathrm{s}$, which is vital not only for their role in regulating peritoneal B-1 cells [14], but also for their own renewal and survival [15, 16]. As shown in Figure 8A, many bacterium-containing vacuoles could be observed in CD $11 \mathrm{~b}^{\text {hi }} / \mathrm{GATA} 6^{\text {bright }} \mathrm{pM \Phi s}$, but not in $\mathrm{CD} 11 \mathrm{~b}^{\text {low }} / \mathrm{GATA}^{\text {faint }}$ cells. In addition, overphagocytosis of viable bacteria might have led to apoptosis (as judged by karyorrhexis) of the former cells, instead of the latter ones, and GATA6 was diffusely distributed in the apoptotic cells. Piperine pre-administration prevented the CD11 $\mathrm{b}^{\text {hi }} / \mathrm{GATA} 6^{\text {bright }} \mathrm{pM}$ Фs from apoptosis, and confined GATA6 within their nuclei. Of note, few CD11b ${ }^{\text {hi }} /$ GATA6 $6^{\text {bright }} \mathrm{pM} \Phi$ s could be observed in either the vehicle or piperine+metformin group, possibly because this cell population had died from infection and thus detached from dishes.
To quantitatively evaluate cell apoptosis, mice were infected with viable $E$. coli and their pMФs were analyzed after intracellular cleaved caspase-3 staining. Caspase-3 is a critical executive protease in apoptosis process [37]. As shown in Figure 8B and 8C, bacterial infection increased cleaved caspase-3 levels in macrophages, suggesting that apoptosis was initiated early $(0.5 \mathrm{~h}$ post infection $)$ after phagocytosis of bacteria. Piperine treatment reduced the cleaved caspase- 3 levels in both $\mathrm{CD} 11 \mathrm{~b}^{+}$and $\mathrm{F} 4 / 80^{+}$ pMФs, but this effect of piperine could be blocked by metformin treatment. Together, these results suggested that piperine treatment (thus enhancing the mTOR activity) protected resident $\mathrm{pM} \Phi \mathrm{s}$ from bacterium-induced apoptotic cell death.

\section{DISCUSSION}

Peritoneal bacterial infection or even bacterial sepsis, due to the penetration of intestinal bacteria, constitutes a great challenge in the treatment of bowel diseases. Here we reported that piperine enhanced the mTORC1 activity by recruiting amino acid transporter to the cell membrane and promoting amino acid metabolism (e.g., glutaminolysis). Such an activity of piperine was linked to its anti-bacterial action at least in resident pMФs of mice. The prophylactic and therapeutic model study demonstrated that piperine were effective for preventing bacterial infection and even for sepsis. To our knowledge, we for the first time reported that a small molecule alkaloid has the capacity to enhance mTORC1 activity and thus fortifies the functions of resident $\mathrm{pM} \Phi \mathrm{s}$.

It has long been established that piperine increases bioavailability of clinical drugs [21, 22], accelerating uptake of amino acids (including Leu) and other nutrients by intestinal epithelial cells [20]. But the mechanism underlying this process is unclear. It was unlikely that Leu could pass through the cell membrane in a nonspecific manner, since it is a large neutral (aliphatic) amino acid relying on distinct transporters for its uptake into cells. Our study provided evidence showing that piperine promoted amino acid metabolism by recruiting more SLC7A5/SLC3A2, the system L1 amino acid transporter for Leu and other large neutral ones, to the cell membrane, which in turn enhanced mTORC1 activation $[18,25]$. Previous reports have indicated that mTOR is a central player in sensing nutrient sufficiency and regulating diverse metabolic processes [18]. Uptake of amino acids, such as Leu and Gln, leads to mTORC1 activation on the lysosomal surface, in a Rag small guanosine triphosphatases (GTPases)dependent or independent manner [23, 38, 39]. Amino acid metabolism and mTORC1 activation may rely on the cell membrane abundance of the transporter, instead of its total cellular protein levels. Supporting this, although the total SLC7A5/SLC3A2 protein levels were greatly suppressed by SLC7A5 knockdown, the mTORC1 
activity in SLC7A5-knocked down cells co-treated with piperine and Leu was still higher than that in control cells treated with Leu alone (Figure 2A and 2B). The uptake of Leu by SLC7A5 has been reported to be required for the metabolic reprograming (mTOR activation) essential for $\mathrm{T}$ cell differentiation in response to antigens [40]. At certain circumstances, such as hepatitis B virus infection [41], T cells may upregulate SLC7A5 expression to meet the requirement for Leu and metabolic reprograming. Thus, likely acting through a similar mechanism, piperine pharmacologically potentiates $\mathrm{mTORC1}$ activation by reprogramming amino acid metabolism.

Our study demonstrated that increased mTORC1 activation by piperine enhanced the functions of resident pMФs, including their bacterial phagocytic ability and LPS-induced cytokine-producing capacity. Consistent with the role of mTOR signaling in cell survival [36], our results also demonstrated that piperine administration prevented F4/80 hi resident pMФs from apoptosis. Due to such functional enhancements of resident $\mathrm{pM \Phi s,} \mathrm{piperine}$ enhanced bacterial clearance and protected mice against bacterial infection in the peritoneal cavity. Therefore,
A

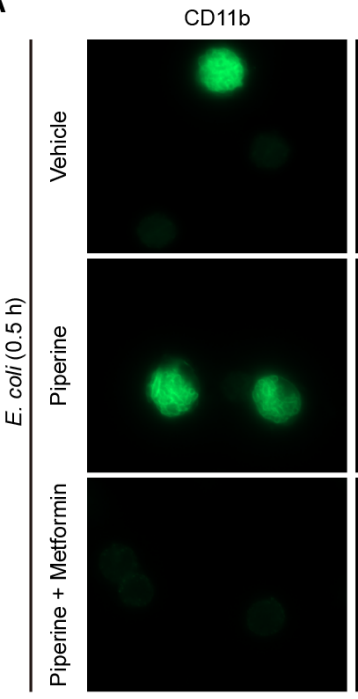

B
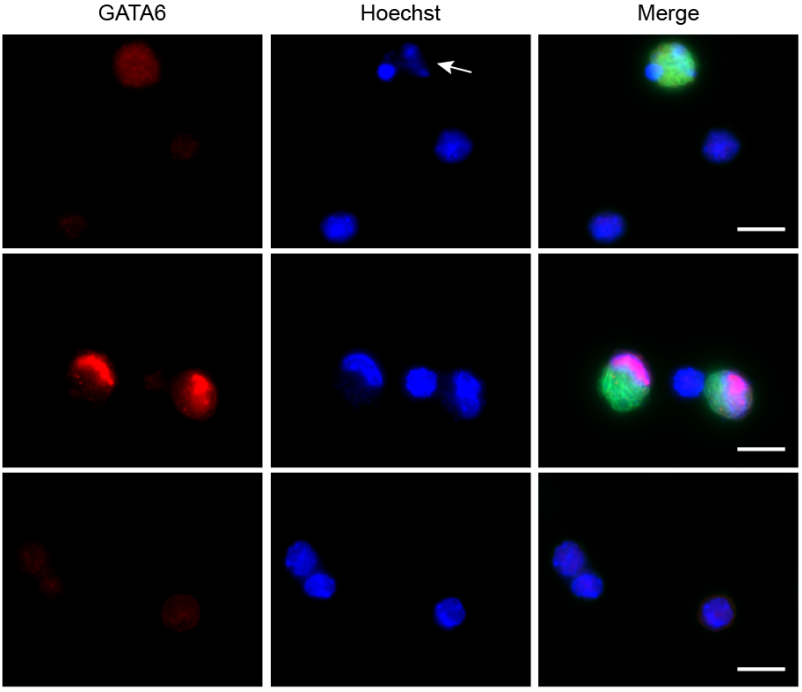

E. coli $(0.5 \mathrm{~h})$
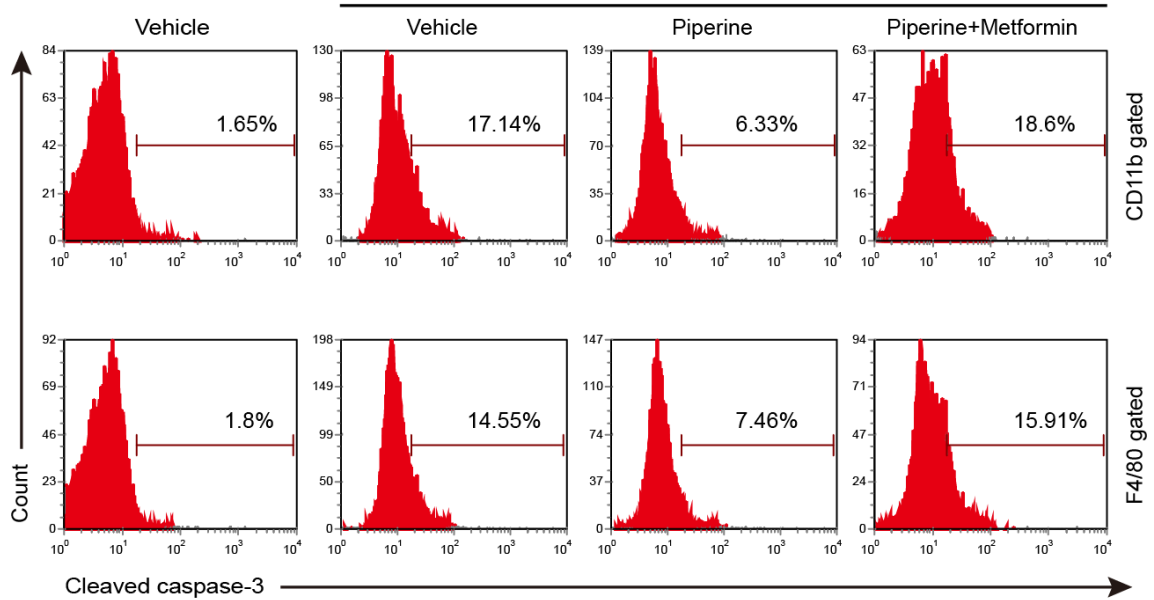

C
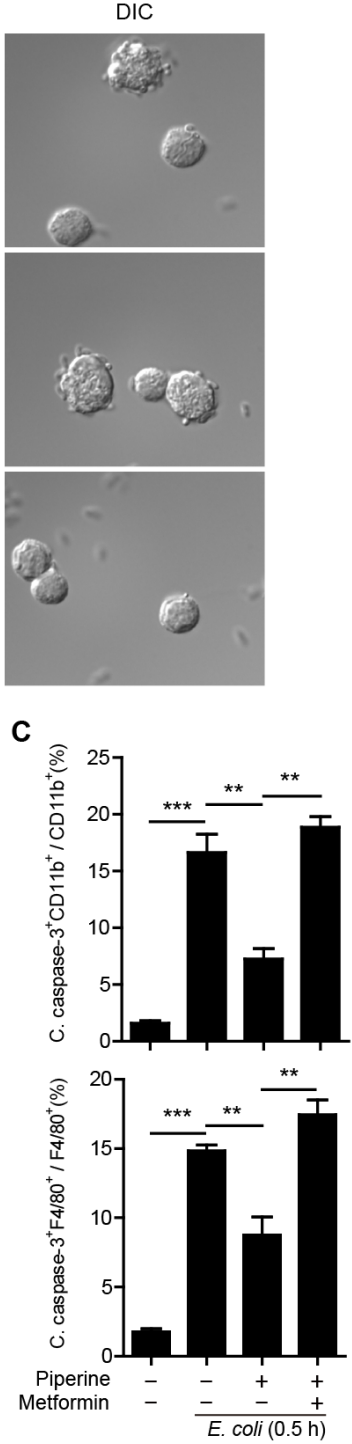

Figure 8: Piperine protects resident peritoneal macrophages from bacterium-induced apoptosis. A. Mice ( $n=5$ for each group) were administered with piperine $(20 \mathrm{mg} / \mathrm{kg})$ or piperine plus metformin $(250 \mathrm{mg} / \mathrm{kg})$ intragastrically once and $4 \mathrm{~h}$ later were injected with viable E. coli $\left(0.5 \times 10^{9} \mathrm{CFU} /\right.$ mouse $)$ intraperitoneally for $0.5 \mathrm{~h}$. The peritoneal cells were isolated and seeded in glass-bottom culture dishes. After washing, the macrophages were fixed and stained with CD11b (green), GATA6 (red) and Hoechst 33342 (blue). Images were captured by fluorescence microscopy. DIC images are also shown. The arrow indicates karyorrhexis. Scale bars, $10 \mu \mathrm{m}$. B. Mice were treated as in A. and their peritoneal macrophages were isolated and stained with CD11b, F4/80 antibody, followed by intracellular staining with cleaved caspase- 3 antibody. One representative flow cytometry plots of 3 independent experiments are shown. C. Quantitative analysis of the percentages of cleaved caspase-3 positive cells in $\mathrm{CD} 11 \mathrm{~b}^{+}$or F4/80 macrophages. Data are expressed as mean $\pm \mathrm{SD}(n=5)$. The significance was estimated by Student's $t$-test. $* * P<0.01 ; * * * P<0.001$. 
the mTORC1-upregulatory capacity of piperine is of clinical significance: it may provide protection against infection for humans in a state of sub-malnutrition (in which the mTORC1 activity is below normal levels), such as in the case of inflammatory bowel disease (IBD) $[13,42]$. In support of this hypothesis, uptake of amino acids and hence activation of $\mathrm{mTOR}$ are required for the maintenance of intestinal homeostasis [13], whereas malnutrition or suppression of mTOR activity induces colitis due to dysregulated innate immune functions of the intestine [43].

In recent years, many studies focused on the immunoregulatory action of mTOR signaling in macrophages $[44,45]$. It has been reported that the fungal cell wall component $\beta$-glucan can prime monocytes/ macrophages to mount an enhanced innate response against fungal infection by activating the mTOR pathway. One characteristic of $\beta$-glucan-primed monocytes is their enhanced ability to secrete IL- 6 and TNF- $\alpha$ upon pathogen stimulation [28]; the authors named such immunological memory traits of innate immune cells as "trained immunity". Consistent with this finding, our data demonstrated that enhanced mTORC1 activity in piperinepretreated cells was linked to increased IL- 6 and TNF- $\alpha$ expression and enhanced phagocytic capacity of resident pMФs, as blocking the mTOR pathway by specific inhibitors attenuated all these effects of piperine. These results suggest that piperine and $\beta$-glucan may act through certain common mechanisms for enhancing the innate functions of monocytes/macrophages to prevent pathogen infection, but further investigation is required to clarify this issue.

It has been known that IL- 6 and TNF- $\alpha$ secretion by macrophages upon bacterial infection in turn enhances their phagocytic capacity, thus promoting the clearance of pathogens [31, 46, 47]. Indeed, increased IL-6 and TNF- $\alpha$ production was correlated with enhanced bacterial clearance in piperine-administered mice compared to control mice (Figure 6F). Immunofluorescence observation demonstrated that it was the LPMs (CD11b $^{\text {bright }}$ GATA6 ${ }^{\text {bright }}$ ), instead of SPMs, robustly engulfed bacteria (Figure 8A). These results demonstrated that the resident $\mathrm{pM} \Phi \mathrm{s}$ were the major bacterial phagocytic cells at least at the early stage of infection and that their phagocytic capacity was enhanced by piperine treatment. In light of the notion that IL- 6 and TNF- $\alpha$ promote wound healing and tissue repair [48-50], increased production of these cytokines may also limit pathogens from penetrating the epithelial lining of the intestine and invading into the peritoneal cavity to induce sepsis, an extreme case of IBD [51].

In summary, we demonstrated that piperine promoted amino acid metabolism and thus enhanced the mTORC1 activation in peritoneal resident macrophages, resulting in potentiation of their innate functions against bacterial infection, alleviating bacterial septic shock. Our study highlights the value of piperine not only as a major ingredient in daily seasoning for promoting appetite and digestion, but also as an mTORC1 booster to enhance the innate immunity of tissue-resident macrophages in fighting against diverse pathogens in certain clinical settings.

\section{MATERIALS AND METHODS}

\section{Reagents and animals}

LPS (E. coli 0111:B4), dimethyl sulfoxide (DMSO), Tween-80, Hoechst 33342 and amino acid transporter inhibitor BCH (2-amino-2-norbornanecarboxylic acid) were bought from Sigma-Aldrich (St. Louis, MO, USA). Thioglycollate medium (Brewer modified) was obtained from Becton Dickinson (Sparks, MD, USA). Piperine was purchased from Guangzhou Institute for Drug Control (Guangzhou, China), dissolved in DMSO and stored at $-20{ }^{\circ} \mathrm{C}$. Rabbit antibodies against phospho(p)-p70S6K, p70S6K, p-4E-BP1, 4E-BP1, p-S6(Ser235/236), GATA6, cleaved caspase-3, SLC7A5, SLC3A2, mTOR, and $\beta$-tubulin were purchased from Cell Signaling Technology (Danvers, MA, USA). The mouse antibody against LAMP2 was obtained from Abcam (Cambridge, MA, USA). PE-F4/80, FITC-CD11b, AlexaFluor488-CD11b, and APC-MHCII were obtained from eBioscience (San Diego, CA, USA). DMEM medium, fetal bovine serum (FBS), penicillin and streptomycin were products of Invitrogen (Carlsbad, CA, USA).

Female C57BL/6 mice were bought from the Experimental Animal Center of Southern Medical University (Guangzhou, China). Animal experiments were designed following National Institutes of Health guidelines and were approved by the Committee on the Ethics of Animal Experiments of Jinan University.

\section{Bacterial preparation}

E. coli strain DH5 $\alpha$ were grown in Luria Broth (LB) media and shaken overnight at $37^{\circ} \mathrm{C}$, and then reinoculated into fresh $\mathrm{LB}$ at $10 \%$ for $3 \mathrm{~h}$ at $37^{\circ} \mathrm{C}$. Bacteria cells were pelleted by centrifugation at $1824 \times \mathrm{g}$ for 10 min, washed with $10 \mathrm{ml}$ PBS twice, and resuspended in appropriate volume of PBS. Cell density was determined using an ultraviolet-visible spectrophotometer (Nanodrop 2000; Thermo Scientific) and the corresponding colonyforming units (CFU) were determined on LB agar plates. For some experiments, viable $E$. coli cells were stained with $40 \mu \mathrm{M}$ carboxyfluorescein diacetate, succinimidyl ester (CFSE), washed and then inactivated for $1 \mathrm{~h}$ at 70 ${ }^{\circ} \mathrm{C}$ in water bath. 


\section{Bacterial infection}

Mice were acclimated for one week. Viable E. coli DH5 $\alpha$ resuspended in $0.5 \mathrm{ml}$ of PBS was injected into the peritoneal cavity (i.p.), and the lethal $\left(2 \times 10^{9} \mathrm{CFU}\right)$ and sub-lethal doses $\left(1 \times 10^{9} \mathrm{CFU}\right)$ were determined by preliminary experiments, which induced peritonitis or even severe sepsis. Piperine (dissolved in 2\% Tween- 80 in PBS as a suspension) or vehicle (2\% Tween-80 in PBS) was given intragastrically (i.g.) before or after bacterial infection. In the former model, mice were administered with piperine at a dose of 10 or $20 \mathrm{mg} / \mathrm{kg}$ once a day for 3 $\mathrm{d}$ consecutively prior to bacterial infection $\left(2 \times 10^{9} \mathrm{CFU}\right)$; in the latter model, mice were infected with bacteria $\left(1 \times 10^{9}\right.$ $\mathrm{CFU}$ ) and $1 \mathrm{~h}$ later were given with $20 \mathrm{mg} / \mathrm{kg}$ piperine for only once. Mouse survival was monitored every $6 \mathrm{~h}$ for $4 \mathrm{~d}$. In another experiment, the bacterial burden in the peritoneal cavity of mice was determined. The mice were sacrificed and peritoneal lavage fluids were collected with $1.5 \mathrm{ml}$ PBS. Serial dilutions were made of the lavage fluids and then incubated overnight at $37{ }^{\circ} \mathrm{C}$ on LB agar plates; CFUs of bacteria were counted and calculated.

\section{Peritoneal macrophage isolation}

For in vitro study, mice were sacrificed by cervical dislocation and sterilized by $70 \%$ ethanol. Peritoneal macrophages were immediately isolated by washing the peritoneal cavity with washing buffer (sterile PBS containing 5\% newborn calf serum and $0.5 \mathrm{mM}$ EDTA). The extracted solution was centrifuged at $300 \times \mathrm{g}$ for 10 min and isolated cells were cultured at $37{ }^{\circ} \mathrm{C}$ in DMEM plus $10 \% \mathrm{FBS}, 100 \mathrm{U} / \mathrm{ml}$ penicillin and $100 \mu \mathrm{g} / \mathrm{ml}$ streptomycin (complete medium). After 2-h incubation, unattached cells were discarded and attached macrophages were further cultured in fresh complete medium. In some experiments, C57BL/6 mice were first injected via i.p. with $1 \mathrm{ml}$ of $3 \%$ thioglycollate (TG). Peritoneal macrophages were isolated $4 \mathrm{~d}$ post the injection.

\section{Cell line culture}

Human cervical cancer HeLa cells, prostate cancer LNCaP cells and mouse macrophage cell line RAW 264.7 was obtained from the Cell Bank of the Chinese Academy of Sciences (Shanghai, China). Cells were maintained in complete DMEM medium and were cultured at $37^{\circ} \mathrm{C}$ in a humidified incubator with $5 \% \mathrm{CO}_{2}$.

\section{Determination of soluble cytokines}

Proinflammatory cytokine proteins in cell culture medium or mouse peritoneal cavity lavage fluids were determined by Cytometric Bead Array (CBA) mouse inflammation kit (BD Biosciences; San Jose, CA, USA) according to the manufacturer's instructions.

\section{Western blotting}

HeLa, LNCaP, and RAW 264.7 cells were seeded in plastic flasks and cultured for $24 \mathrm{~h}$ and then changed with new culture medium with indicated doses of piperine. Whole cell lysates and Western blotting were performed as previously described [11].

\section{Immunofluorescence microscopy}

Immunofluorescent staining was performed essentially as previously described [52]. Briefly, peritoneal macrophages were cultured in glass-bottom dishes, fixed, permeabilized and immunostained with rabbit anti-p-S6 antibody or anti-GATA6 antibody and AlexaFluor488CD11b, followed by CF568-conjugated goat-anti-rabbit IgG (Biotium, Hayward, CA, USA). HeLa cells were immunostained with rabbit anti-mTOR antibody and mouse anti-LAMP2 antibody, or anti-SLC3A2 antibody alone, followed by CF488A-conjugated goat-anti-mouse IgG (Biotium) and/or CF568-conjugated goat-anti-rabbit IgG. Nuclei were revealed by Hoechst 33342 staining. Cells were observed using a Zeiss Axio Observer D1 microscope with a Zeiss EC Plan-Neofluar $100 \times / 1.30$ Oil M27 objective (Carl Zeiss MicroImaging GmbH, Göttingen, Germany). Fluorescence images were captured with a Zeiss AxioCam MR R3 cooled CCD camera controlled with ZEN software (ZEISS).

\section{Histopathology}

After mice were sacrificed, liver and small intestine were harvested, fixed in 4\% neutral formaldehyde, and stained with haemotoxylin and eosin (H\&E). Images were captured under a microscope armed with a color CCD (Zeiss Axio Observer D1).

\section{Knockdown of SLC7A5}

HeLa were seeded in 6-well plates (Corning) (for Western blotting) or glass bottom culture dishes (NEST, China) (for immunofluorescent staining) for $24 \mathrm{~h}$. SLC7A5 siRNAs and negative control were produced by Ribobio (Guangzhou, China). The SLC7A5-specific siRNA sequence is 5'-GCAUCGGCUUCACCAUCAUdTdT-3' targeting 5'-GCATCGGCTTCACCATCAT-3'. Knockdown of SLC7A5 was performed using Lipofectamine RNAiMAX (Invitrogen) according to the instructions provided by the manufacturer. The siRNA was added to each well at a final siRNA concentration of 100 $\mathrm{nM}$. Six hours later, cells were cultured in normal medium 
containing 10\% FBS. After being cultured for another 72 $\mathrm{h}$, cells were used for mTOR activation experiment with Gln, Leu and/or piperine.

\section{Flow cytometry}

For determination cell phenotypes or intracellular protein expression, cells were stained with antibodies, respectively, according to the manufacturers' instructions. CBA beads or cells were analyzed on a flow cytometer (FACSCalibur; Becton Dickinson, Mountain View, CA, USA), and data were acquired using the CELLQuest software (Becton Dickinson).

\section{Statistical analysis}

All experiments were performed independently at least three times, with one representative experiment shown. Data are presented as mean \pm standard deviation (SD). Statistical analysis was performed using Graphpad Prism 4.0 (GraphPad; San Diego, CA). One-way analysis of variance (ANOVA) followed by Tukey's multiple comparison test and unpaired Student's $t$ test (2 tailed) were used to analyze the statistical significance among multiple groups and between two groups, respectively. Kaplan-Meier survival curves were adopted for analysis of mice survival, and the statistical difference between 2 groups was determined using the nonparametric Mann-Whitney $U$ test. $P$ values $<0.05$ were considered statistically significant.

\section{ACKNOWLEDGMENTS}

We thank M. H. Xia for excellent technical assistance in histopathology research. We are also grateful for the assistance in establishing mouse intragastric administration method by Y. Wang. This work was supported by the grants from the National Natural Science Foundation of China (No. 81373423 and No. 81173604).

\section{CONFLICTS OF INTEREST} interests.

The authors declare that they have no competing

\section{REFERENCES}

1. Wattanathorn J, Chonpathompikunlert P, Muchimapura S, Priprem A and Tankamnerdthai O. Piperine, the potential functional food for mood and cognitive disorders. Food Chem Toxicol. 2008; 46:3106-3110.

2. Pattanaik S, Hota D, Prabhakar S, Kharbanda P and Pandhi P. Effect of piperine on the steady-state pharmacokinetics of phenytoin in patients with epilepsy. Phytother Res. 2006;
20:683-686.

3. Jwa H, Choi Y, Park UH, Um SJ, Yoon SK and Park T. Piperine, an LXRalpha antagonist, protects against hepatic steatosis and improves insulin signaling in mice fed a highfat diet. Biochem Pharmacol. 2012; 84:1501-1510.

4. Bai YF and $\mathrm{Xu} \mathrm{H}$. Protective action of piperine against experimental gastric ulcer. Acta Pharmacol Sin. 2000; 21:357-359.

5. Umar S, Golam Sarwar AH, Umar K, Ahmad N, Sajad M, Ahmad S, Katiyar CK and Khan HA. Piperine ameliorates oxidative stress, inflammation and histological outcome in collagen induced arthritis. Cell Immunol. 2013; 284:51-59.

6. Bae GS, Kim MS, Jung WS, Seo SW, Yun SW, Kim SG, Park RK, Kim EC, Song HJ and Park SJ. Inhibition of lipopolysaccharide-induced inflammatory responses by piperine. Eur J Pharmacol. 2010; 642:154-162.

7. Mehmood MH and Gilani AH. Pharmacological basis for the medicinal use of black pepper and piperine in gastrointestinal disorders. J Med Food. 2010; 13:10861096.

8. Fingar DC and Blenis J. Target of rapamycin (TOR): an integrator of nutrient and growth factor signals and coordinator of cell growth and cell cycle progression. Oncogene. 2004; 23:3151-3171.

9. Thoreen CC, Chantranupong L, Keys HR, Wang T, Gray NS and Sabatini DM. A unifying model for mTORC1mediated regulation of mRNA translation. Nature. 2012; 485:109-U142.

10. Wullschleger $\mathrm{S}$, Loewith $\mathrm{R}$ and Hall MN. TOR signaling in growth and metabolism. Cell. 2006; 124:471-484.

11. Pan $\mathrm{H}, \mathrm{Xu}$ LH, Ouyang DY, Wang Y, Zha QB, Hou $\mathrm{XF}$ and $\mathrm{He} \mathrm{XH}$. The second-generation mTOR kinase inhibitor INK128 exhibits anti-inflammatory activity in lipopolysaccharide-activated RAW 264.7 cells. Inflammation. 2014; 37:756-765.

12. Powell JD, Pollizzi KN, Heikamp EB and Horton MR. Regulation of immune responses by mTOR. Annu Rev Immunol. 2012; 30:39-68.

13. Hashimoto $\mathrm{T}$, Perlot $\mathrm{T}$, Rehman $\mathrm{A}$, Trichereau J, Ishiguro H, Paolino M, Sigl V, Hanada T, Hanada R, Lipinski S, Wild B, Camargo SM, Singer D, et al. ACE2 links amino acid malnutrition to microbial ecology and intestinal inflammation. Nature. 2012; 487:477-481.

14. Okabe $\mathrm{Y}$ and Medzhitov R. Tissue-specific signals control reversible program of localization and functional polarization of macrophages. Cell. 2014; 157:832-844.

15. Gautier EL, Ivanov S, Williams JW, Huang SCC, Marcelin G, Fairfax K, Wang PL, Francis JS, Leone P, Wilson DB, Artyomov MN, Pearce EJ and Randolph GJ. Gata6 regulates aspartoacylase expression in resident peritoneal macrophages and controls their survival. J Exp Med. 2014; 211:1525-1531.

16. Rosas M, Davies LC, Giles PJ, Liao CT, Kharfan B, Stone TC, O'Donnell VB, Fraser DJ, Jones SA and Taylor PR. 
The transcription factor Gata6 links tissue macrophage phenotype and proliferative renewal. Science. 2014; 344:645-648.

17. Verrey F, Closs EI, Wagner CA, Palacin M, Endou H and Kanai Y. CATs and HATs: the SLC7 family of amino acid transporters. Pflugers Arch. 2004; 447:532-542.

18. Hara K, Yonezawa K, Weng QP, Kozlowski MT, Belham C and Avruch J. Amino acid sufficiency and mTOR regulate p70 S6 kinase and eIF-4E BP1 through a common effector mechanism. J Biol Chem. 1998; 273:14484-14494.

19. Dunlop EA and Tee AR. Mammalian target of rapamycin complex 1: signalling inputs, substrates and feedback mechanisms. Cell Signal. 2009; 21:827-835.

20. Johri RK, Thusu N, Khajuria A and Zutshi U. Piperinemediated changes in the permeability of rat intestinal epithelial cells. The status of gamma-glutamyl transpeptidase activity, uptake of amino acids and lipid peroxidation. Biochem Pharmacol. 1992; 43:1401-1407.

21. Shoba G, Joy D, Joseph T, Majeed M, Rajendran R and Srinivas PS. Influence of piperine on the pharmacokinetics of curcumin in animals and human volunteers. Planta Med. 1998; 64:353-356.

22. Dudhatra GB, Mody SK, Awale MM, Patel HB, Modi CM, Kumar A, Kamani DR and Chauhan BN. A comprehensive review on pharmacotherapeutics of herbal bioenhancers. TheScientificWorldJournal. 2012; 2012:637953.

23. Duran RV, Oppliger W, Robitaille AM, Heiserich L, Skendaj R, Gottlieb E and Hall MN. Glutaminolysis activates Rag-mTORC1 signaling. Mol Cell. 2012; 47:349358.

24. Li M, Li CH, Allen A, Stanley CA and Smith TJ. The structure and allosteric regulation of mammalian glutamate dehydrogenase. Arch Biochem Biophys. 2012; 519:69-80.

25. Nicklin P, Bergman P, Zhang BL, Triantafellow E, Wang H, Nyfeler B, Yang HD, Hild M, Kung C, Wilson C, Myer VE, MacKeigan JP, Porter JA, et al. Bidirectional transport of amino acids regulates mTOR and autophagy. Cell. 2009; 136:521-534.

26. Yanagida O, Kanai Y, Chairoungdua A, Kim DK, Segawa H, Nii T, Cha SH, Matsuo H, Fukushima J, Fukasawa Y, Tani Y, Taketani Y, Uchino H, et al. Human L-type amino acid transporter 1 (LAT1): characterization of function and expression in tumor cell lines. Biochim Biophys Acta. 2001; 1514:291-302.

27. Sanchez-Margalet V, Goldfine ID, Vlahos CJ and Sung CK. Role of phosphatidylinositol-3-kinase in insulin receptor signaling: studies with inhibitor, LY294002. Biochem Biophys Res Commun. 1994; 204:446-452.

28. Cheng SC, Quintin J, Cramer RA, Shepardson KM, Saeed S, Kumar V, Giamarellos-Bourboulis EJ, Martens JH, Rao NA, Aghajanirefah A, Manjeri GR, Li Y, Ifrim DC, et al. mTOR- and HIF-1alpha-mediated aerobic glycolysis as metabolic basis for trained immunity. Science. 2014; 345:1250684.
29. Hirai H, Sootome H, Nakatsuru Y, Miyama K, Taguchi S, Tsujioka K, Ueno Y, Hatch H, Majumder PK, Pan BS and Kotani H. MK-2206, an allosteric Akt inhibitor, enhances antitumor efficacy by standard chemotherapeutic agents or molecular targeted drugs in vitro and in vivo. Mol Cancer Ther. 2010; 9:1956-1967.

30. Brown EJ, Albers MW, Shin TB, Ichikawa K, Keith CT, Lane WS and Schreiber SL. A mammalian protein targeted by G1-arresting rapamycin-receptor complex. Nature. 1994; 369:756-758.

31. Imanishi J. Expression of cytokines in bacterial and viral infections and their biochemical aspects. J Biochem. 2000; 127:525-530.

32. Goncalves NS, Ghaem-Maghami M, Monteleone G, Frankel G, Dougan G, Lewis DJM, Simmons CP and MacDonald TT. Critical role for tumor necrosis factor alpha in controlling the number of lumenal pathogenic bacteria and immunopathology in infectious colitis. Infect Immun. 2001; 69:6651-6659.

33. Rakoff-Nahoum S, Paglino J, Eslami-Varzaneh F, Edberg $\mathrm{S}$ and Medzhitov R. Recognition of commensal microflora by toll-like receptors is required for intestinal homeostasis. Cell. 2004; 118:229-241.

34. Ghosn EEB, Cassado AA, Govoni GR, Fukuhara T, Yang Y, Monack DM, Bortoluci KR, Almeida SR, Herzenberg LA and Herzenberg LA. Two physically, functionally, and developmentally distinct peritoneal macrophage subsets. Proc Natl Acad Sci U S A. 2010; 107:2568-2573.

35. Barth MW, Hendrzak JA, Melnicoff MJ and Morahan PS. Review of the macrophage disappearance reaction. J Leukoc Biol. 1995; 57:361-367.

36. Edinger $\mathrm{AL}$ and Thompson $\mathrm{CB}$. Akt maintains cell size and survival by increasing mTOR-dependent nutrient uptake. Mol Biol Cell. 2002; 13:2276-2288.

37. Shalini S, Dorstyn L, Dawar S and Kumar S. Old, new and emerging functions of caspases. Cell Death Differ. 2015; 22:526-539.

38. Jewell JL, Kim YC, Russell RC, Yu FX, Park HW, Plouffe SW, Tagliabracci VS and Guan KL. Metabolism. Differential regulation of mTORC1 by leucine and glutamine. Science. 2015; 347:194-198.

39. Wang S, Tsun ZY, Wolfson RL, Shen K, Wyant GA, Plovanich ME, Yuan ED, Jones TD, Chantranupong L, Comb W, Wang T, Bar-Peled L, Zoncu R, et al. Metabolism. Lysosomal amino acid transporter SLC38A9 signals arginine sufficiency to mTORC1. Science. 2015; 347:188-194.

40. Sinclair LV, Rolf J, Emslie E, Shi YB, Taylor PM and Cantrell DA. Control of amino-acid transport by antigen receptors coordinates the metabolic reprogramming essential for $\mathrm{T}$ cell differentiation. Nat Immunol. 2013; 14:500-508.

41. Pallett LJ, Gill US, Quaglia A, Sinclair LV, Jover-Cobos M, Schurich A, Singh KP, Thomas N, Das A, Chen A, Fusai 
G, Bertoletti A, Cantrell DA, et al. Metabolic regulation of hepatitis B immunopathology by myeloid-derived suppressor cells. Nat Med. 2015; 21:591-600.

42. Altomare R, Damiano G, Abruzzo A, Palumbo VD, Tomasello G, Buscemi S and Lo Monte AI. Enteral nutrition support to treat malnutrition in inflammatory bowel disease. Nutrients. 2015; 7:2125-2133.

43. Nakamura A, Hara K, Yamamoto K, Yasuda H, Moriyama H, Hirai M, Nagata M and Yokono K. Role of the mTOR complex 1 pathway in the in vivo maintenance of the intestinal mucosa by oral intake of amino acids. Geriatrics \& gerontology international. 2012; 12:131-139.

44. Weichhart T, Costantino G, Poglitsch M, Rosner M, Zeyda M, Stuhlmeier KM, Kolbe T, Stulnig TM, Horl WH, Hengstschlager M, Muller M and Saemann MD. The TSCmTOR signaling pathway regulates the innate inflammatory response. Immunity. 2008; 29:565-577.

45. Xie S, Chen M, Yan B, He X, Chen X and Li D. Identification of a role for the PI3K/AKT/mTOR signaling pathway in innate immune cells. PLoS One. 2014; 9:e94496.

46. Kopf M, Baumann H, Freer G, Freudenberg M, Lamers M, Kishimoto T, Zinkernagel R, Bluethmann H and Kohler G. Impaired immune and acute-phase responses in interleukin6-deficient mice. Nature. 1994; 368:339-342.

47. Kroesen S, Widmer AF, Tyndall A and Hasler P. Serious bacterial infections in patients with rheumatoid arthritis under anti-TNF-alpha therapy. Rheumatology (Oxford). 2003; 42:617-621.

48. Kuhn KA, Manieri NA, Liu TC and Stappenbeck TS. IL-6 stimulates intestinal epithelial proliferation and repair after injury. PLoS One. 2014; 9:e114195.

49. Petreaca ML, Do D, Dhall S, McLelland D, Serafino A, Lyubovitsky J, Schiller N and Martins-Green MM. Deletion of a tumor necrosis superfamily gene in mice leads to impaired healing that mimics chronic wounds in humans. Wound Repair Regen. 2012; 20:353-366.

50. Brancato SK and Albina JE. Wound macrophages as key regulators of repair origin, phenotype, and function. Am J Pathol. 2011; 178:19-25.

51. Smith AM, Rahman FZ, Hayee B, Graham SJ, Marks DJ, Sewell GW, Palmer CD, Wilde J, Foxwell BM, Gloger IS, Sweeting T, Marsh M, Walker AP, et al. Disordered macrophage cytokine secretion underlies impaired acute inflammation and bacterial clearance in Crohn's disease. J Exp Med. 2009; 206:1883-1897.

52. Ouyang DY, Xu LH, He XH, Zhang YT, Zeng LH, Cai JY and Ren S. Autophagy is differentially induced in prostate cancer LNCaP, DU145 and PC-3 cells via distinct splicing profiles of ATG5. Autophagy. 2013; 9:20-32. 